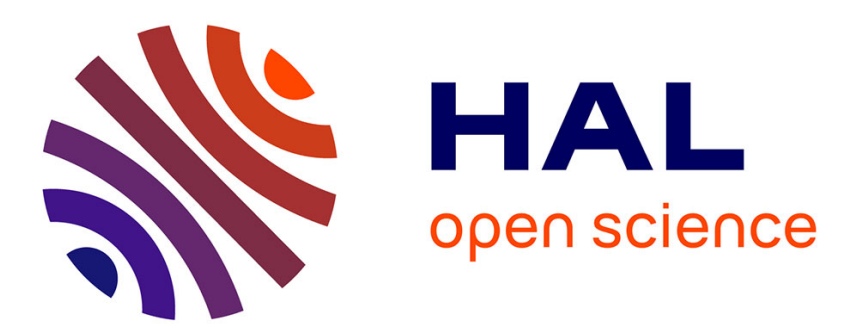

\title{
Deposition of complement C3c, IgG4 and IgG at the basement membrane of pancreatic ducts and acini in autoimmune pancreatitis
}

Sönke Detlefsen, Jan H Bräsen, Giuseppe Zamboni, Paola Capelli, Günter Klöppel

\section{To cite this version:}

Sönke Detlefsen, Jan H Bräsen, Giuseppe Zamboni, Paola Capelli, Günter Klöppel. Deposition of complement C3c, IgG4 and IgG at the basement membrane of pancreatic ducts and acini in autoimmune pancreatitis. Histopathology, 2010, 57 (6), pp.825. 10.1111/j.1365-2559.2010.03717.x . hal-00601174

\section{HAL Id: hal-00601174 \\ https://hal.science/hal-00601174}

Submitted on 17 Jun 2011

HAL is a multi-disciplinary open access archive for the deposit and dissemination of scientific research documents, whether they are published or not. The documents may come from teaching and research institutions in France or abroad, or from public or private research centers.
L'archive ouverte pluridisciplinaire $\mathbf{H A L}$, est destinée au dépôt et à la diffusion de documents scientifiques de niveau recherche, publiés ou non, émanant des établissements d'enseignement et de recherche français ou étrangers, des laboratoires publics ou privés. 


\section{Histopathology}

\section{Deposition of complement C3c, IgG4 and IgG at the basement membrane of pancreatic ducts and acini in autoimmune pancreatitis}

\begin{tabular}{|r|l|}
\hline Journal: & Histopathology \\
\hline Manuscript ID: & HISTOP-01-10-0046.R1 \\
\hline Manuscript Type: & Original Article \\
\hline Author: & 06-Mar-2010 \\
\hline Complete List of Authors: & $\begin{array}{l}\text { Detlefsen, Sönke; Odense University Hospital, Department of } \\
\text { Pathology; University Hospital Schleswig-Holstein, Campus Kiel, } \\
\text { Department of Pathology } \\
\text { Bräsen, Jan; University Hospital Schleswig-Holstein, Campus Kiel, } \\
\text { Department of Pathology } \\
\text { Zamboni, Giuseppe; University of Verona, Ospedale Sacro Cuore- } \\
\text { Don Calabria, Department of Pathology } \\
\text { Capelli, Paola; University of Verona, Policlinico G. B. Rossi, } \\
\text { Department of Pathology } \\
\text { Klöppel, Günter; University Hospital Schleswig-Holstein, Campus } \\
\text { Kiel, Department of Pathology; Technical University of Munich, } \\
\text { Department of Pathology }\end{array}$ \\
\hline Keywords: & $\begin{array}{l}\text { Autoimmune pancreatitis, IgG4, granulocytic epithelial lesions } \\
\text { (GELs), immune complex, complement C3 }\end{array}$ \\
\hline
\end{tabular}

\section{ScholarONE" \\ Manuscript Central}




\section{Deposition of complement C3c, IgG4 and IgG at the basement membrane of pancreatic ducts and acini in autoimmune pancreatitis}

Sönke Detlefsen ${ }^{1,2,3}$, Jan Hinrich Bräsen ${ }^{1}$, Giuseppe Zamboni ${ }^{4}$, Paola Capelli ${ }^{5}$ and Günter $\mathrm{K}_{10 ̈ p p e l}{ }^{1,6}$

${ }^{1}$ Department of Pathology, University Hospital Schleswig-Holstein, Campus Kiel, Kiel, Germany

${ }^{2}$ Department of Pathology, Odense University Hospital, Odense, Denmark

${ }^{3}$ Department of Clinical Pathology, Vejle Hospital, Vejle, Denmark

${ }^{4}$ Department of Pathology, University of Verona, Ospedale Sacro Cuore-Don Calabria, Negrar-Verona, Italy

${ }^{5}$ Department of Pathology, University of Verona, Policlinico G. B. Rossi, Verona, Italy

${ }^{6}$ Department of Pathology, Technical University of Munich, Munich, Germany

Running title: Immunopathology of autoimmune pancreatitis

Word count: 3.431

Key words: Autoimmune pancreatitis, IgG4, granulocytic epithelial lesions (GELs), complement C3, immune complex, immunopathology

Abbreviations: AIP, autoimmune pancreatitis; BM, basement membrane; CK7, cytokeratin 7; FITC, fluorescein isothyocyanate; GELs, granulocytic epithelial lesions; HPF, high power field; IF, immunofluorescence

\section{Corresponding author:}

Sönke Detlefsen, MD, $\mathrm{PhD}$

Department of Pathology

Odense University Hospital

Winsløwparken 15, 5000 Odense C, Denmark

E-mail: S.Detlefsen@gmx.net

Tel: +4565414343

Fax: +45 66122783 


\section{ABSTRACT}

Aims: Autoimmune pancreatitis (AIP) is a type of pancreatitis whose immunopathogenesis is still unknown. It has been reported that kidney biopsy specimens from patients diagnosed with both AIP and tubulointerstitial nephritis revealed deposits at tubular basement membranes (BMs) containing complement C3, IgG and also IgG4. Our aim was to investigate the deposition of complement and immunoglobulins in pancreatic tissue from AIP patients compared to non-AIP patients.

Methods: On frozen pancreatic tissue from AIP and alcoholic chronic pancreatitis (ACP) patients, double immunofluorescence microscopy for $\mathrm{C} 3 \mathrm{c}, \mathrm{IgG} 4$ and $\mathrm{IgG}$ together with $\mathrm{CK} 7$, trypsin, collagen IV, CD31 and CD79a as well as immunofluorescence microscopy for C1q, IgA and IgM were performed.

Results: In AIP patients, complement C3c, IgG4 and IgG were deposited at the collagen IVpositive BM of pancreatic and bile ducts and of acini. In a minority of the ACP patients, weak C3c-positive BM deposits were detected, but no IgG4- or IgG-positive BM deposits were present in ACP.

Conclusion: The deposition of $\mathrm{C} 3 \mathrm{c}, \mathrm{IgG} 4$ and $\mathrm{IgG}$ at the $\mathrm{BM}$ of small and medium-sized ducts and acini of the pancreas is characteristic of AIP. This suggests that immune complexmediated destruction of ducts and acini may play a role in the pathogenesis of AIP. 


\section{INTRODUCTION}

Autoimmune pancreatitis (AIP) is a special type of chronic pancreatitis whose clinical, serological and histological features suggest that immune mechanisms are involved in its pathogenesis. Histologically, lymphoplasmacytic infiltrates focusing on pancreatic ducts and acini are the most prominent feature of AIP. ${ }^{1-6}$ Immunohistochemically, there is usually a predominance of CD4-positive Th1 cells over Th2 cells ${ }^{7}$ and the expression of HLA-DR on pancreatic epithelial cells. ${ }^{8}$ AIP patients in Japan show a particular HLA two-loci haplotype, DRB1*0405-DQB1*0401. ${ }^{9}$ Moreover, autoimmune antibodies such as antinuclear antibody (ANA), anti-lactoferrin (ALF) and anti-carbonic anhydrase II (ACA-II) ${ }^{7}$ have been observed serologically in AIP patients.

In 2001, Hamano et al. reported that IgG4 serum levels were markedly elevated in patients with AIP. ${ }^{10}$ Subsequently, Kamisawa and coworkers observed a diffuse infiltration of IgG4-positive plasma cells not only in the pancreas of AIP patients, but also in other organs and proposed the existence of a new clinicopathological entity of IgG4-related sclerosing disease that included autoimmune pancreatitis, retroperitoneal fibrosis, sclerosing sialadenitis and sclerosing cholangitis. ${ }^{11,12}$ Finally, tubulointerstitial nephritis, sometimes forming pseudotumors, membranous nephropathy and IgG4-related diffuse pulmonary inflammatory nodules were added to the spectrum of IgG4-related disorders. ${ }^{13-20}$

The pathogenic role of IgG4 in the IgG4-related disease complex is so far unknown. Renal biopsy specimens from AIP patients with tubulointerstitial nephritis revealed that granular deposits at the tubular basement membranes (BMs) contain IgG4. ${ }^{14}$ Pancreatic tissue that was examined in the same study also showed electron dense granular deposits at basal membrane structures, although neither the affected tissue components nor the biochemical composition of the deposits were clarified. ${ }^{14}$ In a subsequent study, Deshpande's group identified not only IgG4 in the deposits at the renal tubular BMs but also complement $\mathrm{C} 3$, and occasionally $\operatorname{IgG} 1, \operatorname{IgG} 2$ and $\operatorname{IgG} 3 .^{13}$ Recently, it was reported that $6 / 10$ patients with hypocomplementemia of unknown aetiology had elevated serum-IgG4 levels, ${ }^{21}$ and, conversely, that of 28 patients with IgG4-related systemic disease nine had hypocomplementaemia and 15 increased serum levels of circulating immune complexes. ${ }^{22}$ Interestingly, Aoki and colleagues reported data indicating that there are tissue-specific IgG4 autoantibodies in the sera of patients with AIP. ${ }^{23}$ They demonstrated that epithelial cells of the pancreas, bile duct, salivary gland and stomach in tissue specimens obtained from patients without an autoimmune disease stained positive for IgG4 after incubation with the sera of AIP 
patients. ${ }^{23}$ However, Aoki et al. also concluded that yet no AIP-specific antigens have been identified.

Because the above data suggest that AIP may be a systemic immune complexmediated disease related to the expression of IgG4, our study attempted to identify IgG4positive immune complexes in pancreatic tissue specimens from AIP patients. We therefore performed double immunofluorescence microscopy for $\mathrm{C} 3 \mathrm{c}$, IgG4 and IgG combined with cytokeratin 7 (CK7), trypsin, collagen IV, CD31 and CD79a and immunofluorescence microscopy for $\mathrm{C} 1 \mathrm{q}$, $\operatorname{Ig} \mathrm{A}$ and $\operatorname{IgM}$ in frozen pancreatic tissue from six patients with the clinical and morphological diagnosis of AIP and in one patient with IgG4-positive sclerosing cholangitis as extrapancreatic manifestation of AIP. A comparison of the results with those from seven patients with alcoholic chronic pancreatitis (ACP) revealed that the findings were specific to AIP patients.

\section{MATERIALS AND METHODS}

\section{Patients and tissues}

In the archives and the consultation files of the Departments of Pathology of the University Hospital Schleswig-Holstein, Campus Kiel, Germany, and the University of Verona, Italy, 88 pancreatic resection specimens with a postoperative diagnosis of AIP were identified in the period between 1987 and 2009. Snap-frozen tissue and paraffin-embedded formalin-fixed tissue blocks were obtained from surgical specimens from six patients (three men and three women; mean age 64.5 years; range 49 to 76 years), who had undergone pancreaticoduodenectomy between 2000 and 2009 and presented with a mass-forming lesion located in the head of the pancreas. Additional frozen and paraffin-embedded tissues were obtained from a cholecystectomy and extrahepatic bile duct resection specimen from a 63year-old male patient with jaundice. All patients were treated surgically because of suspected pancreatic or bile duct cancer. The well established criteria for the morphological diagnosis of this disease, ${ }^{4,5,24,39}$ which are included in both the first version of the HISORt criteria and the proposal for revised HISORt criteria (Mayo Clinic, Rochester, USA) for the diagnosis of AIP, were used. ${ }^{24,25}$ Histopathological examination of the resected tissue revealed AIP in six patients. In $5 / 6$ patients there were increased numbers ( $>20$ per HPF) of IgG4-positive plasma cells infiltrating the pancreatic tissue. The sixth patient with AIP who showed granulocytic epithelial lesions (GELs) had only very few $(<2$ per HPF) IgG4-positive plasma cells. The 
seventh patient was diagnosed with IgG4-positive ( $>20$ IgG4-positive plasma cells per HPF) sclerosing cholangitis as extrapancreatic manifestation of AIP.

For comparison with the AIP tissues, snap-frozen tissue and paraffin-embedded formalin-fixed tissue blocks from pancreatic resection specimens from seven patients (four women and three men; mean age 50.4 years; range 37 to 64 years) whose pancreatic changes fulfilled the morphological criteria for the diagnosis of alcoholic chronic pancreatitis (ACP) and who had a history of chronic alcohol abuse were examined. ${ }^{26-30}$ These patients were all treated by pancreaticoduodenectomy between 1999 and 2009 because of intractable pain, jaundice and/or suspected pancreatic cancer. In addition, a snap-frozen tissue block containing normal pancreatic tissue was obtained from a left-sided pancreatic resection specimen, which was removed together with the stomach and spleen in a case of advanced gastric cancer.

\section{Histology and immunohistochemistry}

The sections from the paraffin blocks were stained with hematoxylin $\&$ eosin. In addition, one section per AIP case was immunostained for IgG4 using a monoclonal mouse antibody (The Binding Site, Birmingham, UK, clone HP6025, 1:100) and the EnVision staining technique (Dako A/S, Glostrup, Denmark). The sections were first pretreated for antigen demasking by boiling in citrate-buffered saline for $3.5 \mathrm{~min}$. Endogenous phosphatase activity was blocked with $1 \mathrm{mM}$ levamisole in the substrate solution. Normal tonsillar tissue as well as autoimmune pancreatitis tissue served as controls.

\section{Immunofluorescence microscopy}

On $7 \mu \mathrm{m}$ thick sections of snap frozen tissues from the seven AIP patients, the seven ACP patients and the normal pancreatic specimen, immunofluorescence microscopy for $\mathrm{C} 1 \mathrm{q}, \mathrm{C} 3 \mathrm{c}$, $\mathrm{IgA}, \mathrm{IgG}, \mathrm{IgG} 4$ and $\mathrm{IgM}$ and immunofluorescence double staining for $\mathrm{C} 3 \mathrm{c}$, IgG and $\operatorname{IgG} 4$ together with CK7, trypsin, collagen IV, CD31 and CD79a were performed. After cutting, the sections were air dried for $30 \mathrm{~min}$ and fixed in cold acetone for $10 \mathrm{~min}$. They were rinsed twice for $5 \mathrm{~min}$ in phosphate-buffered saline at $\mathrm{pH}$ 7.3. The sections were then incubated with $100 \mu \mathrm{l}$ of the fluorescein isothyocyanate (FITC)-conjugated polyclonal rabbit antibody directed against C1q (Dako A/S, F0254, working dilution 1:20), C3c (Dako A/S, F0201, working dilution 1:80), IgA (Dako A/S, F0204, working dilution 1:30), IgG (Dako A/S, F0202, working dilution 1:30) and IgM (Dako A/S, F0203, working dilution 1:20) for 60 min at room temperature and subsequently rinsed in phosphate-buffered saline for $10 \mathrm{~min}$ in the 
dark. IgG4 was detected indirectly, using the monoclonal mouse antibody mentioned above, followed by incubation for $30 \mathrm{~min}$ in the dark with donkey Fab fragment anti-mouse IgG antibody conjugated with Cy 2 (Dianova, Hamburg, Germany, Code 715-226-150, diluted $1: 100)$.

For the immunofluorescence double stainings, the incubation with the FITCconjugated antibodies to $\mathrm{C} 3 \mathrm{c}$ and $\mathrm{IgG}$ and the incubation with the antibody to IgG4 followed by incubation with the Cy 2-conjugated anti-mouse IgG antibody was preceded by incubation with mouse antibodies to CK7 (Medac, Hamburg, Germany, clone OV-TL12/30, working dilution 1:50)), collagen IV (Medac, Hamburg, Germany, clone PHM-12+CIV22, working dilution 1:50), CD31 (Dako A/S, clone JC70A, working dilution 1:50), CD79a (Dako A/S, clone JCB117, working dilution 1:50), or trypsin (Ventrex Laboratories, Portland, OR, USA, working dilution 1:100). These slides were afterwards incubated with anti-mouse donkey IgG antibodies conjugated with Alexa 555 (Invitrogen, Karlsruhe, Germany, A-31570, 1:50) in the dark for $30 \mathrm{~min}$ and then rinsed in phosphate-buffered saline for $10 \mathrm{~min}$. All slides were mounted with Vectashield Hard Set Mounting Medium with DAPI (Vector Laboratories, Burlingame, USA $(\mathrm{H}-1500))$.

The intensity of the immunofluorescence signal was scored as 0 if there was no immunoreactivity at the $\mathrm{BM}$ of ducts and acini; 1 if there was focal and weak immunoreactivity; 2 if the immunoreactivity was focal and strong; 3 if it was diffuse and weak; and 4 if it was diffuse and strong.

\section{Statistical analysis}

The nonparametric Mann-Whitney $U$ test was used for intergroup differences. $P$ values of $<0.05$ were considered significant. All statistical tests were performed using SPSS 10.0 for Windows (SPSS Inc., Chicago, IL, USA).

\section{RESULTS}

\section{Clinical follow-up of the AIP patients}

During follow-up (mean follow-up period 33 months, range 5 to 96 months), 2/6 AIP patients developed other immune-related disorders. One had asthma (see also Table 1), and the second patient had both Crohn's disease in the ileum and psoriatic arthritis, for the latter of which he was treated with methotrexate. Serum-IgG4 levels were measured in three AIP patients and proved to be elevated in $2 / 3$ (i.e. above $140 \mathrm{mg} / \mathrm{dL}$ ). In the third patient in whom IgG4 was 
measured serologically the level was in the normal range. This was the patient who lacked strong infiltration with IgG4-positive plasma cells (see below) and instead showed granulocytic epithelial lesions (GELs) in the pancreatic tissue. One patient was treated with steroids prior to surgery but showed only a partial response. No malignant disease was diagnosed in any of the patients.

\section{Histology and immunohistochemistry}

Histologically, intense lymphoplasmacytic infiltration, particularly around medium-sized ducts, was observed in the tissues of all six AIP patients from whom pancreatic tissue was available (Figure 1A and Table 1). In five of these six AIP patients a dense infiltration with IgG4-positive plasma cells in the pancreatic tissue $(>20$ IgG4 positive plasma cells per high power field (HPF)) was observed (Figure 1C and Table 1). Granulocytic epithelial lesions (GELs) of the pancreas ${ }^{5}$ were only detected in the AIP patient who lacked strong infiltration with IgG4-positive plasma cells (Figure 1D and Table 1). In the patient with IgG4-positive sclerosing cholangitis, dense infiltration with IgG4-positive plasma cells was found in the wall of the extrahepatic bile duct (Figure 1B). All cases showed moderate to severe fibrosis and venulitis. The pancreatic tissues from the seven patients with ACP displayed predominantly interlobular fibrosis of varying extent (Table 2). Moreover, they had irregularly dilated ducts with protein plugs and/or calculi, areas of fat tissue necrosis in resorption, pseudocysts and sparse aggregates of lymphocytes and some macrophages. Diffuse and/or periductal lymphoplasmacytic infiltration and GELs were lacking.

\section{Immunofluorescence microscopy}

Table 1 summarizes the clinical and pathological findings in the AIP patients together with the scored intensity of the immunofluorescence signals. Granular deposits of complement C3c and granular and linear deposits of IgG4 (in addition to IgG4-positive plasma cells) were detected at the base of interlobular and intralobular pancreatic duct cells labelled by cytokeratin 7 , and focally also along the base of acini labelled by trypsin in all and 5/6 AIP patients, respectively (Figure 2 and 3). The patient with IgG4-positive sclerosing cholangitis had granular C3c- and granular/linear IgG4-positive deposits in the BM area of the peribiliary tubular glands in the wall of the extrahepatic bile duct. Figure 4 illustrates the colocalization of $\mathrm{C} 3 \mathrm{c}$ and IgG4 with collagen IV (representing the main type of collagen in BMs) in the BM area of small pancreatic ducts and acini. IgG-positive deposits were observed in all examined 
pancreatic tissues. They were distributed diffusely and in the wall of vessels. However, weak IgG-positivity in the BM areas of pancreatic ducts was only detected in AIP patients, including the patient with GELs (Figure 5D-F). This patient had also granular deposits of C3c in the BM area of ducts and acini (Figure $5 \mathrm{~A}-\mathrm{C}$ ).

Table 2 summarizes the clinical and pathological findings in the ACP patients together with the scored intensity of the immunofluorescence signals. Of the ACP patients only three displayed a few weakly C3c-positive deposits in the BM areas. In the remaining ACP patients and in the normal pancreatic tissue, weak C3c-positivity was only observed in the wall of blood vessels. The difference in the IF scores for the deposition of $\mathrm{C} 3 \mathrm{c}$ at the BM in AIP versus ACP was statistically significant $(\mathrm{p}<0.005)$. None of the non-AIP pancreatic tissues showed any IgG4 deposits associated with epithelial cells or plasma cells. In these tissues, staining was only observed in the wall of blood vessels. Similarly, IgG-positivity was lacking in the BM areas of pancreatic ducts of non-AIP tissues. The difference in the IF scores for the depositions of IgG4 and IgG in AIP versus ACP was statistically significant $(\mathrm{p}<0.005)$.

$\operatorname{IgA}$, IgM or C1q consistently failed to label $\mathrm{BM}$ areas in the pancreatic tissues. $\mathrm{Clq}$ and IgM positivity, however, was observed in the wall of blood vessels in all pancreatic tissues and in some fibrotic foci in the pancreas of AIP and ACP patients. In addition, there were scattered IgA- and IgM-positive plasma cells in the AIP and ACP specimens.

\section{DISCUSSION}

Since Hamano demonstrated in 2001 that AIP is associated with changes in the serum levels of $\operatorname{IgG} 4^{10}$ and Kamisawa described an IgG4-related disease complex affecting not only the pancreas but a number of other organs, the pathogenetic significance of IgG4 in AIP has been intensively discussed. ${ }^{12,31}$ Using double immunofluorescence microscopy for the identification of $\mathrm{C} 3 \mathrm{c}$, IgG4 and IgG together with CK7 (ductal cells), trypsin (acinar cells), collagen IV (BMs), CD31 (endothelium of vessels) or CD79a (B-lymphocytes/plasma cells), we determined that tissue from the pancreas of our five IgG4-positive AIP patients and the extrahepatic bile duct of our IgG4-positive sclerosing cholangitis patient contained deposits of complement C3c, IgG4 and IgG (but not C1q, IgA and IgM), which colocalized with BMassociated collagen IV of ducts and acini. This suggests that IgG4 may be bound to immune complexes deposited at structures that are heavily involved in and altered by the fibroinflammatory process characterizing AIP and the commonly associated IgG4-positive sclerosing cholangitis. ${ }^{5}$ 
A clear limitation of this study is the small number of patients examined. This is due to the fact that the immunofluorescence study performed required snap frozen tissue from resected pancreas specimens, which was only available in a few patients of our series of 88 cases. However, since the results are rather uniform in our patients, we believe that our data may contribute to our understanding of the pathogenesis of AIP. The study revealed the deposition of $\mathrm{C} 3 \mathrm{c}$, IgG4 and $\mathrm{IgG}$ at BMs that stained for collagen IV, one of the main components of BMs. These findings were present in all tissue specimens from five patients with IgG4-positive AIP and one patient with AIP-related IgG4-positive sclerosing cholangitis of the extrahepatic bile duct. Of these patients, those in whom serum-IgG4 levels were measured also had elevated IgG4 serum levels. The data proved to be specific to AIP, since no BM deposition of IgG4 and IgG and only weak immunofluorescence signals (in 3/7 ACP patients) for $\mathrm{C} 3 \mathrm{c}$ were found at the $\mathrm{BM}$ in the pancreatic tissues from seven patients with ACP or in normal pancreatic tissue. Pancreatic resection specimens from ACP patients were chosen as control tissue because ACP represents the most common type of chronic pancreatitis in the Western world.

The C3c-positive immunofluorescence signals identified granular deposits, which are typical for complement as a component of immune complexes. The IgG4-positive signals formed a mixed granular-linear pattern, as was also observed for IgG. These deposits were densest along the interlobular pancreatic ducts and the ducts of the accessory glands in the mucosa-submucosa of the extrahepatic bile duct. In cases that also showed intense involvement of the acinar tissue by inflammation and fibrosis, the deposition of C3c, IgG4 and $\operatorname{IgG}$ was also pronounced at this site.

The massive deposition of $\mathrm{C} 3 \mathrm{c}$ in AIP tissue coincides with the recently reported hypocomplementemia observed in a number of patients with IgG4-positive AIP. ${ }^{18,21,22}$ Since increased concentrations of circulating immune complexes were also found in AIP patients, ${ }^{18,21,22}$ it seems that C3c-containing IgG4-positive immune complexes are deposited at the BMs of organs involved in IgG4-related sclerosing disease. The duct changes and the loss of acinar tissue in association with intense lymphoplasmacytic infiltration and fibrosis in AIP suggest that these structures are particularly involved in immune complex-mediated damage to pancreatic tissue. However, both the exact interactions between IgG4 and complement and the role of the IgG4- and C3c-positive deposits in the ongoing inflammatory tissue alterations are still unclear. IgG4 is the only subclass of human $\operatorname{IgG}$ that is unable to activate complement by the classical pathway. However, in mice it has been shown that non-complement activating 
subclasses of antibodies may synergize with other IgG subclasses to activate complement through the lectin pathway. ${ }^{32}$ Moreover, IgG4 has the tendency to interact with other immunoglobulins such as the rheumatoid factor ${ }^{33}$ and reveals an intrinsic affinity for IgG when coated to a solid phase.$^{34}$ These findings suggest that, if IgG4 is not only a bystander in the immune process along the BMs of pancreatic ducts and acini, it might use non-classical pathways for complement activation.

It is also still unclear toward which antigen the immunoglobulins in the deposits along the BMs of pancreatic ducts and acini are directed. Lactoferrin, carbonic anhydrase II and trypsinogen have been discussed as antigens, because these proteins characterize the specialized secretory epithelium that is involved in AIP and other AIP-associated diseases, such as IgG4-positive sclerosing cholangitis, sclerosing sialadenitis or tubulointerstitial nephritis. ${ }^{7}$ Furthermore, neonatal mice have been shown to develop histopathological features of AIP after thymectomy and immunization with lactoferrin and carbonic anhydrase II. $^{35}$ In a recent proteomic analysis, an yet unidentified $13.1 \mathrm{kDa}$ protein was detected that may represent an antigen playing a pathogenic role in the development of IgG4-related systemic disease. $^{22}$ Moreover, Aoki et al. reported that epithelial cells of the pancreas, bile duct, salivary gland and stomach in tissue specimens obtained from patients without an autoimmune disease stained positive for IgG4 after incubation with the sera of AIP patients. ${ }^{23}$ Recently Frulloni et al. identified in $94 \%$ of AIP patients but only in 5\% of pancreatic cancer patients IgG antibodies to a plasminogen-binding protein (PBP) that is homologous to the human ubiquitin-protein ligase E3 component n-recognin 2 (UBR2), which is expressed in pancreatic acinar cells. ${ }^{36}$ However, all the potential antigens mentioned reside in the cytoplasm of pancreatic cells and are not associated with the BMs where we found the deposits of C3c, IgG4 and IgG. This implies that these antigens might only be secondarily involved in the AIP immune process, as it is directed toward still unknown antigens in pancreatic BMs. Alternatively, the BM deposits might be a secondary phenomenon to an immune process in which the primary event and immune reaction remain to be identified.

Our study included one patient whose clinical features were indistinguishable from those of the other AIP patients of our series and who, in addition to the histopathological features of AIP, showed changes of the ducts and acini that have been called GELs (i.e. granulocytic epithelial lesions). ${ }^{5}$ Furthermore, the number of IgG4-positive plasma cells was very low in the lymphoplasmacytic infiltrate, compared to that of the other AIP patients of our series, in which it was increased. Also the serum-level of IgG4 was in the normal range. Due 
to these criteria, this patient can be classified as belonging to a subgroup which has recently been called AIP type 2, ${ }^{37,38}$ and which has been separated from the more common type 1 AIP showing high serum and tissue IgG4-positivity and GEL-negativity. ${ }^{5,39-41}$ Interestingly, this patient failed to show any IgG4-positive deposits associated with the BMs of the ducts and acini, but remained positive for deposits of $\mathrm{C} 3 \mathrm{c}$ and $\mathrm{IgG}$. If this so far unique finding is confirmed in future studies, it would imply that in type 2 AIP the pathomechanisms leading to the changes in the ducts and acini and the development of fibrosis are independent of the effects of IgG4. This again raises the question as to whether IgG4 plays a primary and active role in the pathogenesis of AIP or whether it represents a secondary phenomenon.

In conclusion, our study shows that the deposition of $\mathrm{C} 3 \mathrm{c}$, IgG4 and $\mathrm{IgG}$ in association with the BMs of ducts and acini of the pancreas appears to be a feature of the immunopathology of AIP. Because the ducts and acini represent the main targets of the inflammatory tissue damage in AIP, these findings suggest that the C3c-, IgG4- and IgGpositive deposits may be involved in the pathogenesis of the disease, although their significance is still unclear and needs to be elucidated.

\section{ACKNOWLEDGEMENTS}

We thank Professor Bence Sipos for contributing tissue specimens for this study, and Professor Torben Steiniche for making some of the technical equipment available. Moreover, we are grateful to Tanja Engel and Maike Pacena for their excellent technical assistance and to Kay Dege for editing the manuscript. This work was supported by a grant from the Health Research Fund of Central Denmark Region. 


\section{REFERENCES}

1. Detlefsen S, Sipos B, Zhao J, Drewes AM, Klöppel G. Autoimmune pancreatitis: expression and cellular source of profibrotic cytokines and their receptors. Am J Surg Pathol 2008 May 2;32(7):986-995.

2. Klöppel G, Detlefsen S, Feyerabend B. Fibrosis of the pancreas: the initial tissue damage and the resulting pattern. Virchows Arch. 2004 Jul;445(1):1-8.

3. Klöppel G, Sipos B, Zamboni G, Kojima M, Morohoshi T. Autoimmune pancreatitis: histo- and immunopathological features. J. Gastroenterol. 2007 May;42 Suppl 18:2831.

4. Weber SM, Cubukcu-Dimopulo O, Palesty JA, et al. Lymphoplasmacytic sclerosing pancreatitis: inflammatory mimic of pancreatic carcinoma. J. Gastrointest. Surg. 2003 Jan;7(1):129-137.

5. Zamboni G, Lüttges J, Capelli P, et al. Histopathological features of diagnostic and clinical relevance in autoimmune pancreatitis: a study on 53 resection specimens and 9 biopsy specimens. Virchows Arch. 2004 Dec;445(6):552-563.

6. Kojima M, Sipos B, Klapper W, et al. Autoimmune pancreatitis: frequency, IgG4 expression, and clonality of T and B cells. Am. J. Surg. Pathol. 2007 Apr;31(4):521528.

7. Okazaki K, Uchida K, Ohana M, et al. Autoimmune-related pancreatitis is associated with autoantibodies and a Th1/Th2-type cellular immune response. Gastroenterology 2000 Mar;118(3):573-581.

8. Ectors N, Maillet B, Aerts R, et al. Non-alcoholic duct destructive chronic pancreatitis. Gut 1997 Aug;41(2):263-268.

9. Kawa S, Ota M, Yoshizawa K, et al. HLA DRB10405-DQB10401 haplotype is associated with autoimmune pancreatitis in the Japanese population. Gastroenterology 2002 May;122(5):1264-1269.

10. Hamano $\mathrm{H}$, Kawa $\mathrm{S}$, Horiuchi A, et al. High serum IgG4 concentrations in patients with sclerosing pancreatitis. N. Engl. J. Med. 2001 Mar 8;344(10):732-738.

11. Kamisawa T, Funata N, Hayashi Y, et al. Close relationship between autoimmune pancreatitis and multifocal fibrosclerosis. Gut 2003 May;52(5):683-687.

12. Kamisawa T, Nakajima H, Egawa N, Funata N, Tsuruta K, Okamoto A. IgG4-related sclerosing disease incorporating sclerosing pancreatitis, cholangitis, sialadenitis and retroperitoneal fibrosis with lymphadenopathy. Pancreatology. 2006;6(1-2):132-137.

13. Cornell LD, Chicano SL, Deshpande V, et al. Pseudotumors due to IgG4 immunecomplex tubulointerstitial nephritis associated with autoimmune pancreatocentric disease. Am J Surg Pathol 2007 Oct;31(10):1586-1597. 
14. Deshpande V, Chicano S, Finkelberg D, et al. Autoimmune pancreatitis: a systemic immune complex mediated disease. Am. J. Surg. Pathol. 2006 Dec;30(12):1537-1545.

15. Hirano K, Kawabe T, Komatsu Y, et al. High-rate pulmonary involvement in autoimmune pancreatitis. Intern. Med. J 2006 Jan;36(1):58-61.

16. Imai H, Hamai K, Komatsuda A, Ohtani H, Miura AB. IgG subclasses in patients with membranoproliferative glomerulonephritis, membranous nephropathy, and lupus nephritis. Kidney Int. 1997 Jan;51(1):270-276.

17. Saeki T, Saito A, Yamazaki H, et al. Tubulointerstitial nephritis associated with IgG4related systemic disease. Clin. Exp. Nephrol. 2007 Jun;11(2):168-173.

18. Saeki T, Imai N, Ito T, Yamazaki H, Nishi S. Membranous nephropathy associated with IgG4-related systemic disease and without autoimmune pancreatitis. Clin. Nephrol. 2009 Feb;71(2):173-178.

19. Takeda S, Haratake J, Kasai T, Takaeda C, Takazakura E. IgG4-associated idiopathic tubulointerstitial nephritis complicating autoimmune pancreatitis. Nephrol. Dial. Transplant. 2004 Feb;19(2):474-476.

20. Tsushima K, Tanabe T, Yamamoto $\mathrm{H}$, et al. Pulmonary involvement of autoimmune pancreatitis. Eur. J. Clin. Invest 2009 Aug;39(8):714-722.

21. Saeki T, Ito T, Yamazaki H, Imai N, Nishi S. Hypocomplementemia of unknown etiology: an opportunity to find cases of IgG4-positive multi-organ lymphoproliferative syndrome. Rheumatol. Int. 2009 Apr 18.

22. Yamamoto M, Naishiro Y, Suzuki C, et al. Proteomics analysis in 28 patients with systemic IgG4-related plasmacytic syndrome. Rheumatol. Int. 2009 Jul 17.

23. Aoki S, Nakazawa $\mathrm{T}$, Ohara $\mathrm{H}$, et al. Immunohistochemical study of autoimmune pancreatitis using anti-IgG4 antibody and patients' sera. Histopathology 2005 Aug;47(2):147-158.

24. Chari ST, Takahashi N, Levy MJ, et al. A diagnostic strategy to distinguish autoimmune pancreatitis from pancreatic cancer. Clin. Gastroenterol. Hepatol. 2009 Oct;7(10):1097-1103.

25. Chari ST, Smyrk TC, Levy MJ, et al. Diagnosis of autoimmune pancreatitis: the Mayo Clinic experience. Clin. Gastroenterol Hepatol. 2006 Aug;4(8):1010-1016.

26. Detlefsen S, Sipos B, Feyerabend B, Klöppel G. Fibrogenesis in alcoholic chronic pancreatitis: the role of tissue necrosis, macrophages, myofibroblasts and cytokines. Mod. Pathol. 2006 Aug;19(8):1019-1026.

27. Etemad B, Whitcomb DC. Chronic pancreatitis: diagnosis, classification, and new genetic developments. Gastroenterology 2001 Feb;120(3):682-707.

28. Homma T, Harada H, Koizumi M. Diagnostic criteria for chronic pancreatitis by the Japan Pancreas Society. Pancreas 1997 Jul;15(1):14-15. 
29. Klöppel G, Maillet B. The morphological basis for the evolution of acute pancreatitis into chronic pancreatitis. Virchows Arch. A Pathol. Anat. Histopathol. 1992;420(1):14.

30. Klöppel G. Progression from acute to chronic pancreatitis. A pathologist's view. Surg. Clin. North Am. 1999 Aug;79(4):801-814.

31. Kamisawa T, Okamoto A. Autoimmune pancreatitis: proposal of IgG4-related sclerosing disease. J. Gastroenterol 2006 Jul;41(7):613-625.

32. Murata K, Fox-Talbot K, Qian Z, et al. Synergistic deposition of C4d by complementactivating and non-activating antibodies in cardiac transplants. Am. J. Transplant. 2007 Nov;7(11):2605-2614.

33. Zack DJ, Stempniak M, Wong AL, Weisbart RH. Localization of an Fc-binding reactivity to the constant region of human IgG4. Implications for the pathogenesis of rheumatoid arthritis. J. Immunol. 1995 Nov 15;155(10):5057-5063.

34. Rispens T, Ooievaar-De HP, Vermeulen E, Schuurman J, van der Neut KM, Aalberse RC. Human IgG4 binds to IgG4 and conformationally altered IgG1 via Fc-Fc interactions. J. Immunol. 2009 Apr 1;182(7):4275-4281.

35. Uchida K, Okazaki K, Nishi T, et al. Experimental immune-mediated pancreatitis in neonatally thymectomized mice immunized with carbonic anhydrase II and lactoferrin. Lab Invest 2002 Apr;82(4):411-424.

36. Frulloni L, Lunardi C, Simone R, et al. Identification of a novel antibody associated with autoimmune pancreatitis. N. Engl. J. Med. 2009 Nov 26;361(22):2135-2142.

37. Chari ST, Longnecker DS, Klöppel G. The diagnosis of autoimmune pancreatitis: a Western perspective. Pancreas 2009 Nov;38(8):846-848.

38. Park DH, Kim MD, Chari ST. Recent advances in autoimmune pancreatitis. Gut 2009;58(12):1680-9

39. Notohara K, Burgart LJ, Yadav D, Chari S, Smyrk TC. Idiopathic chronic pancreatitis with periductal lymphoplasmacytic infiltration: clinicopathologic features of 35 cases. Am. J. Surg. Pathol. 2003 Aug;27(8):1119-1127.

40. Zhang L, Notohara K, Levy MJ, Chari ST, Smyrk TC. IgG4-positive plasma cell infiltration in the diagnosis of autoimmune pancreatitis. Mod. Pathol. 2007 Jan;20(1):23-28.

41. Detlefsen S, Drewes AM, Vyberg M, Klöppel G. Diagnosis of autoimmune pancreatitis by core needle biopsy: application of six microscopic criteria. Virchows Arch. 2009 May;454(5):531-539. 


\section{LEGENDS}

Figure 1. Histopathology of the pancreas and the extrahepatic bile duct in patients with autoimmune pancreatitis: A, Pancreatic tissue showing periductal and diffuse lymphoplasmacytic infiltration (hematoxylin and eosin, original magnification $\mathrm{x}$ 50). B, Bile duct mucosa with lymphoplasmacytic infiltration (hematoxylin and eosin, original magnification x 50). C, Periductal lymphoplasmacytic infiltration with many IgG4-positive plasma cells (original magnification x 200). D, Pancreatic duct with granulocytic epithelial lesion (GEL) (hematoxylin and eosin, original magnification x 200).

Figure 2. Double immunofluorescence microscopy in an AIP patient showing granular deposits of complement C3c surrounding a CK7-labelled medium-sized pancreatic duct (A-C, original magnification $\mathrm{x}$ 1000), a CK7-labelled small pancreatic duct (D-F, original magnification x 1000), and a group of acini labelled by trypsin (G-I, original magnification $\mathrm{x}$ 1000).

Figure 3. Double immunofluorescence microscopy in A-C, an AIP patient with infiltration of IgG4-positive plasma cells showing granular deposits of IgG4 surrounding a small CK7labelled pancreatic duct (original magnification x 1000), and D-F, a patient diagnosed with IgG4-positive sclerosing cholangitis showing deposits of IgG4 surrounding CK7-labelled peribiliary tubular glands in the wall of the extrahepatic bile duct (original magnification $\mathrm{x}$ 1000).

Figure 4. Double immunofluorescence microscopy in an AIP patient with infiltration of IgG4-positive plasma cells showing colocalization of granular deposits of C3c (A-C, original magnification x 1000) or IgG4 (D-F, original magnification x 400) with collagen IV labelled basement membranes of small pancreatic ducts and acini.

Figure 5. Double immunofluorescence microscopy in an AIP patient without IgG4-positive plasma cells showing granular deposits of complement C3c (A-C, original magnification $\mathrm{x}$ 400) or IgG (D-F, original magnification x 1000) surrounding small pancreatic ducts labelled by CK7. 
Table 1. Clinical and pathological data on six patients with autoimmune pancreatitis and one patient with IgG4-positive sclerosing cholangitis (patient no. 6).

\begin{tabular}{|c|c|c|c|c|c|c|c|c|c|}
\hline \multirow[b]{2}{*}{ Pat no. } & \multirow[b]{2}{*}{ Age } & \multirow[b]{2}{*}{ Sex } & \multirow[b]{2}{*}{$\begin{array}{c}\text { Other immune } \\
\text { disorders }\end{array}$} & \multicolumn{3}{|c|}{ Histological features } & \multicolumn{3}{|c|}{ Score of IF of BM deposits } \\
\hline & & & & $\begin{array}{c}\text { Lymphoplasmacytic } \\
\text { infiltration }\end{array}$ & $\begin{array}{c}\text { Granulocytic } \\
\text { epithelial lesions } \\
\text { (GELs) }\end{array}$ & $\begin{array}{c}20 \text { IgG4- } \\
\text { positive } \\
\text { plasma cells/ } \\
\text { HPF } \\
\end{array}$ & C3c & IgG4 & IgG \\
\hline 1 & 65 & $\mathrm{~F}$ & no & yes & no & yes & 4 & 2 & 1 \\
\hline 2 & 66 & $\mathrm{M}$ & Asthma & yes & no & yes & 2 & 2 & 1 \\
\hline 3 & 49 & M & $\begin{array}{l}\text { Crohn's disease } \\
\text { Psoriatic arthritis }\end{array}$ & yes & no & yes & 2 & 2 & 1 \\
\hline 4 & 68 & $\mathrm{~F}$ & no & yes & no & yes & 4 & 2 & 1 \\
\hline 5 & 63 & M & no & yes & no & yes & 4 & 2 & 1 \\
\hline 6 & 63 & M & $\begin{array}{l}\text { IgG4-positive } \\
\text { cholecystitis } \\
\text { and } \\
\text { IgG4-positive } \\
\text { extrahepatic } \\
\text { sclerosing } \\
\text { cholangitis } \\
\end{array}$ & yes\# & - & yes & 4 & 2 & 2 \\
\hline 7 & 76 & $\mathrm{~F}$ & no & yes & yes & no & 4 & 0 & 1 \\
\hline
\end{tabular}

BM, basement membrane; F, female; IF, immunofluorescence; M, male. \# in the wall of the extrahepatic bile duct. 
Table 2. Clinical and pathological data on seven patients with alcoholic chronic pancreatitis.

\begin{tabular}{|c|c|c|c|c|c|c|c|c|c|}
\hline \multirow[b]{2}{*}{ Pat no. } & \multirow[b]{2}{*}{ Age } & \multirow[b]{2}{*}{ Sex } & \multirow[b]{2}{*}{ Other disease } & \multicolumn{3}{|c|}{ Histological features } & \multicolumn{3}{|c|}{ Score of IF of BM deposits } \\
\hline & & & & $\begin{array}{c}\text { Interlobular } \\
\text { fibrosis }\end{array}$ & $\begin{array}{c}\text { Necrosis/ } \\
\text { pseudocysts }\end{array}$ & Calculi & $\mathrm{C} 3 \mathrm{c}$ & IgG4 & IgG \\
\hline 1 & 43 & $\mathrm{~F}$ & $\begin{array}{l}\text { Chronic gallstone- } \\
\text { related cholecystitis }\end{array}$ & yes & no & yes & 1 & 0 & 0 \\
\hline 2 & 55 & $\mathrm{~F}$ & $\begin{array}{c}\text { Chronic gallstone- } \\
\text { related cholecystitis } \\
\text { Unspecific } \\
\text { duodenitis }\end{array}$ & yes & yes & no & 1 & 0 & 0 \\
\hline 3 & 37 & M & no & yes & yes & yes & 0 & 0 & 0 \\
\hline 4 & 58 & $\mathrm{~F}$ & $\begin{array}{l}\text { Brunner's gland } \\
\text { adenoma }\end{array}$ & yes & yes & yes & 0 & 0 & 0 \\
\hline 5 & 64 & M & no & yes & yes & yes & 1 & 0 & 0 \\
\hline 6 & 44 & $\mathrm{~F}$ & no & yes & yes & yes & 0 & 0 & 0 \\
\hline 7 & 52 & M & $\begin{array}{c}\text { Meckel's } \\
\text { diverticulum } \\
\text { Chronic gallstone- } \\
\text { related cholecystitis }\end{array}$ & yes & yes & no & 0 & 0 & 0 \\
\hline
\end{tabular}

BM, basement membrane; F, female; IF, immunofluorescence; M, male. 


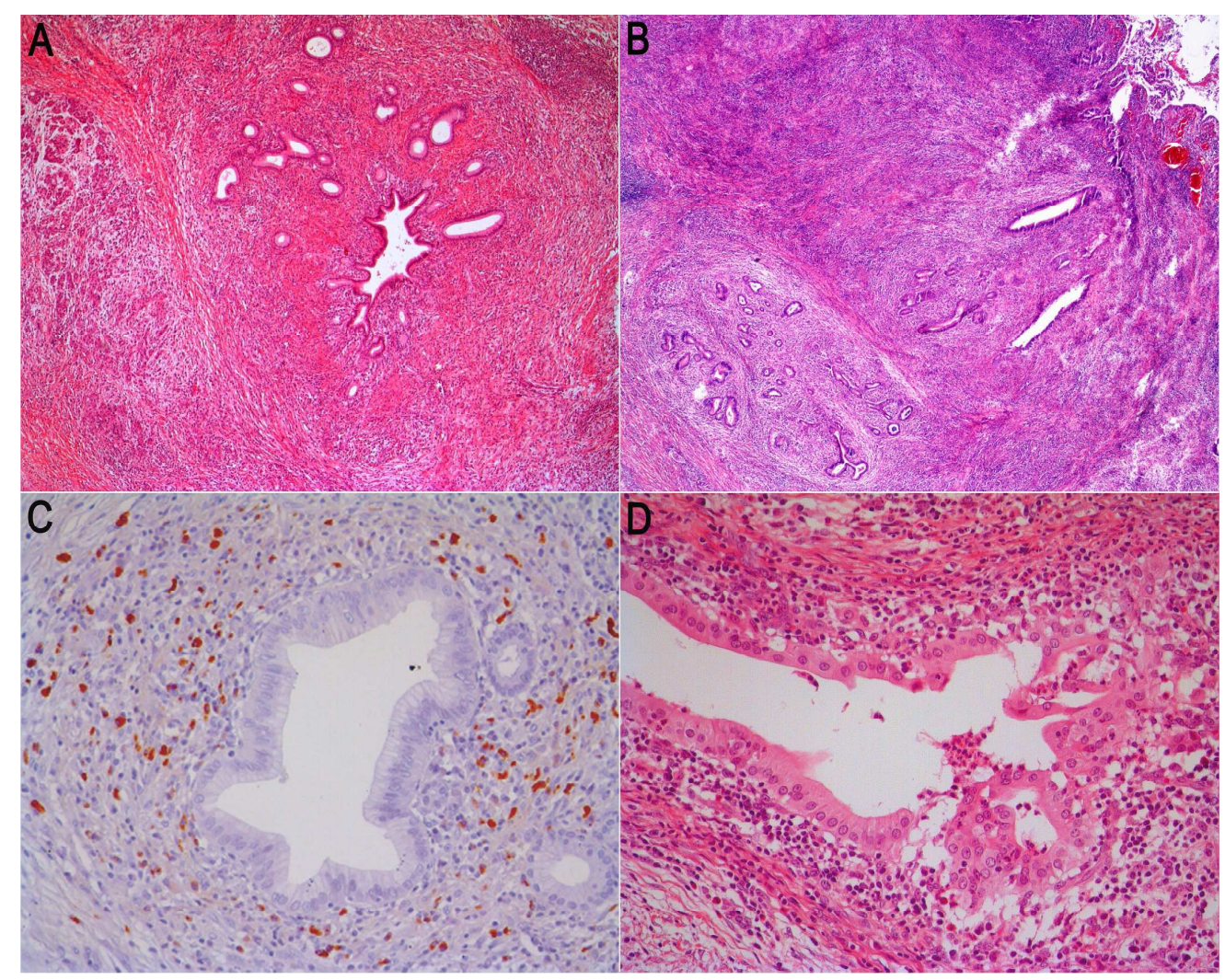

$184 \times 147 \mathrm{~mm}(600 \times 600 \mathrm{DPI})$ 


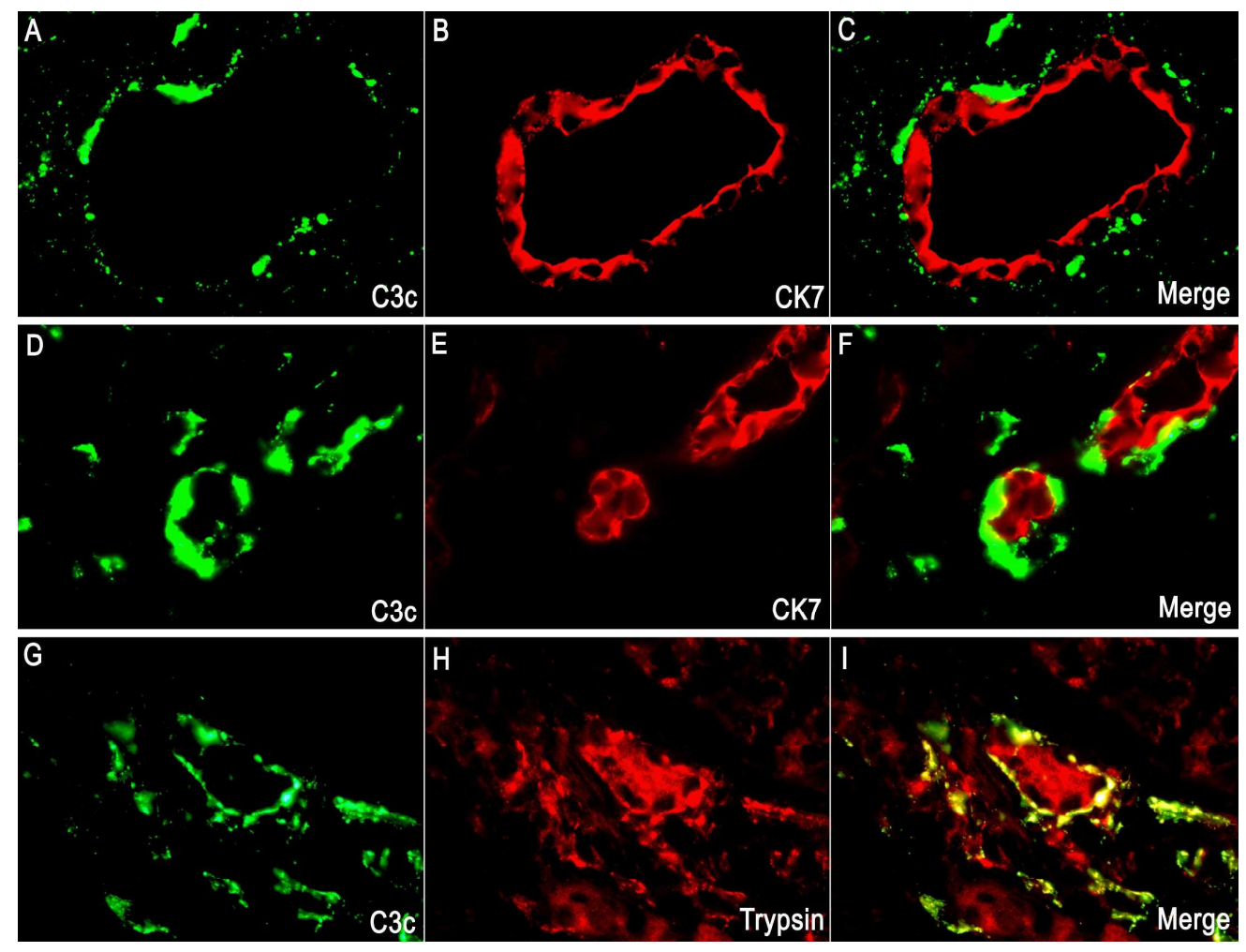

$184 \times 141 \mathrm{~mm}(600 \times 600 \mathrm{DPI})$ 


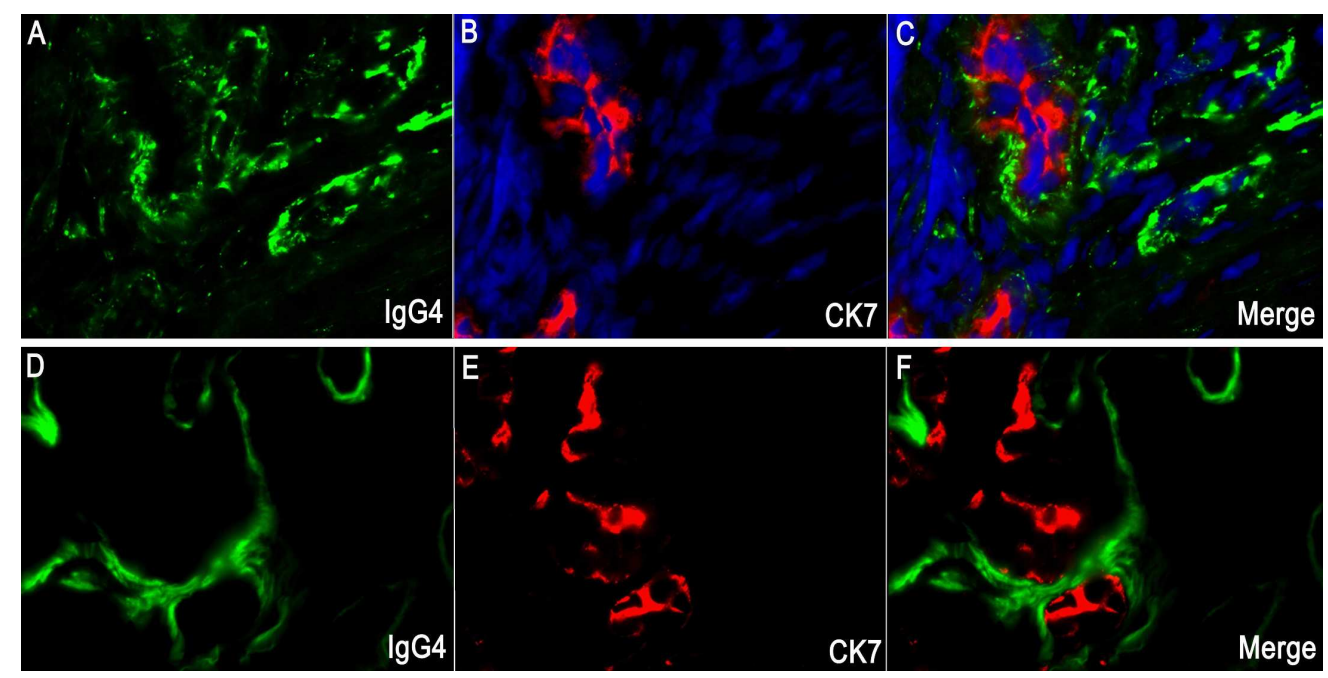

$185 \times 93 \mathrm{~mm}(599 \times 599$ DPI $)$ 

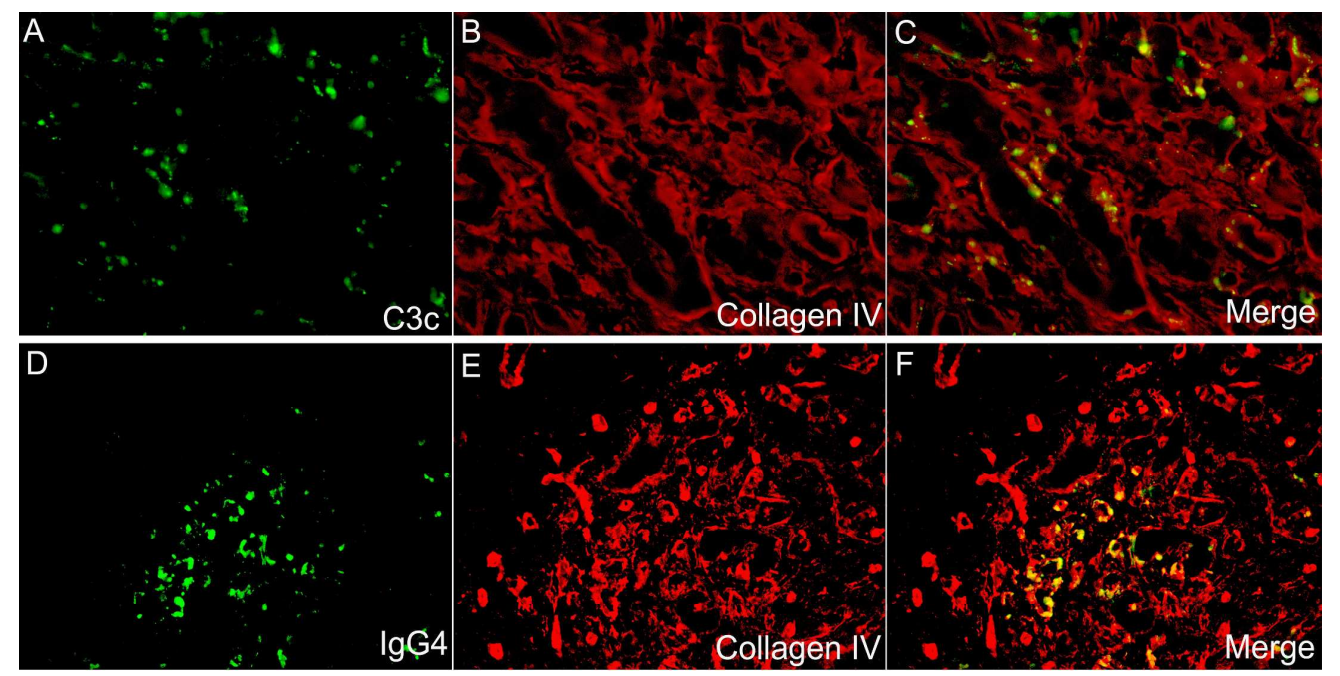

$184 \times 93 \mathrm{~mm}(600 \times 600 \mathrm{DPI})$ 


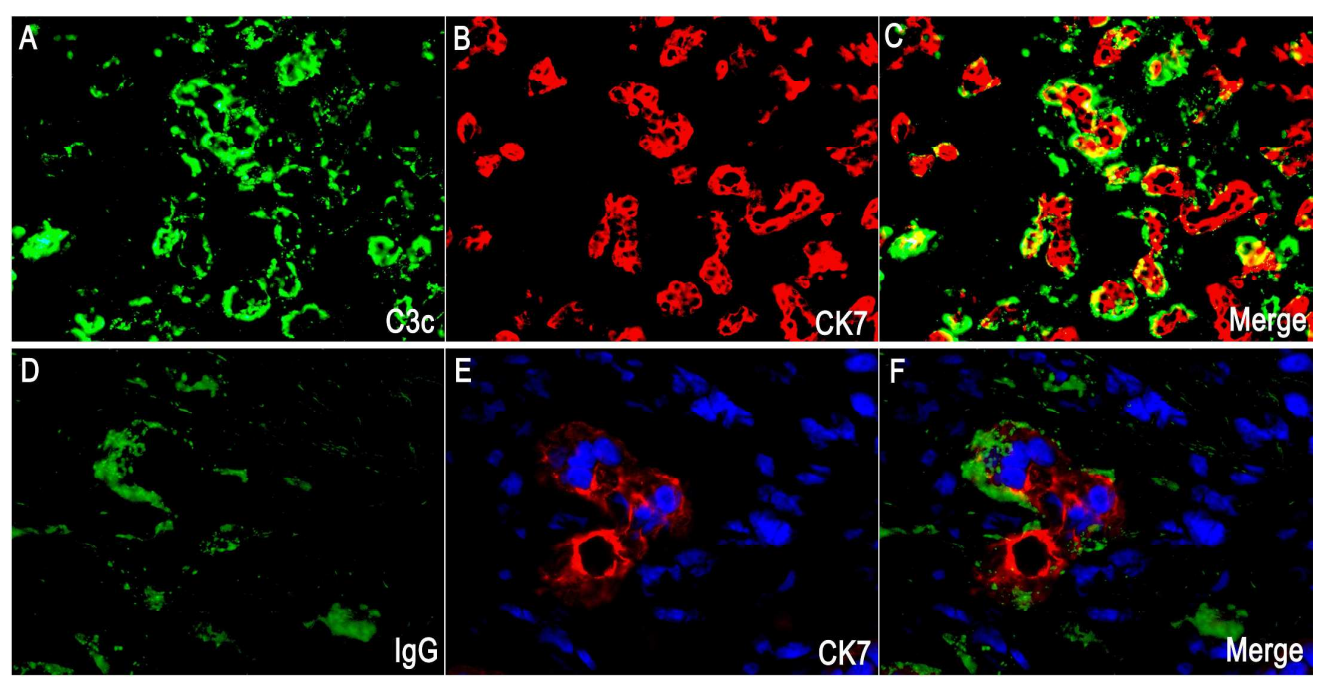

$184 \times 94 \mathrm{~mm}(600 \times 600 \mathrm{DPI})$ 


\section{OUH \\ Odense Universitetshospital}

\section{Professor Michael Wells}

Editor-in-Chief

Histopathology

HISTOP-01-10-0046 - "Deposition of complement C3c, IgG and IgG4 at the basement membrane of pancreatic ducts and acini in autoimmune pancreatitis"

Dear Professor Wells,

We are grateful for your positive evaluation of our manuscript and the valuable critique of the reviewers.

Attached please find the revised manuscript that we would like to resubmit. All changes that were made are marked in red. Besides, some small changes in the spelling and wording were made, but these are not marked in red.

Our point-by-point response to the comments of the two reviewers is as follows:

\section{Referee: 1}

Point 1: "It is accepted that the alcoholic pancreatitis group was a well defined clinical group. Would it have been possible to include other types of pancreatitis? Perhaps the authors could explain why they only included alcoholic pancreatitis in their control group."

On page 9, at the end of paragraph 1, we have added an explanation why pancreatic tissues from patients with alcoholic chronic pancreatitis were chosen as control material.

\author{
Afdeling for Klinisk Patologi \\ Winsløwparken 15 \\ 5000 Odense C \\ Denmark \\ Kontakt: Dr. Sönke Detlefsen, MD, PhD \\ E-mail: \\ S.Detlefsen@gmx.net \\ sonke.detlefsen@ouh.fyns-amt.dk \\ Phone: +4565414343 \\ Fax: +4566122783 \\ 6. marts 2010 \\ Side $1 / 3$
}




\section{OUH \\ Odense Universitetshospital}

6. marts 2010

Side $2 / 3$

Point 2: "The pictures are clear and illustrate the findings well. In the abstract it is stated that "......IgG and IgG4 were deposited at the collagen IV positive basement membrane of small and medium-sized pancreatic and bile ducts and also of acini." It is accepted that the IgG4 may be present along the BM, assuming that subepithelial localisation indicates BM deposition. However, double staining for IgG4 and basement membrane antigens is not recorded or shown. Was it done? Again the text of the results section concludes that there was BM localisation of IgG4. The evidence that lgG4 is indeed present in the BM or, specifically, in the collagen IV positive basement membrane, should perhaps be discussed in a little more detail. Similarly, the methods and results section might elaborate on the way in which the basement membrane was identified. Is subepithelial localisation a completely reliable guide? Unless there is stronger evidence that the IgG4 is localised in the collagen IV positive BM, a more cautious statement may be appropriate, particularly in the abstract."

We have added a new series of illustrations (Figure 4D-F in the revised manuscript), showing the colocalization of $\mathrm{C} 3 \mathrm{C}$ and IgG4 with BM-associated collagen IV in AIP. Figure 3G-I of the original manuscript (showing already the colocalization of C3c with collagen IV) is now labelled Figure 4A$\mathrm{C}$, and Figure 4 of the original manuscript is labelled Figure 5.

Point 3: "A few US spellings are used. These need to be altered (e.g., "etiology" on page 3).“

We changed a few US spellings to British spelling.

Point 4: "Some minor typographical errors are present, e.g., misplaced full stops on page 10. "

We apologize for the typographical errors and hope to have eliminated all of them in the revised manuscript.

Referee: 2

Point 1: "In the 'Abstract', the authors describe findings of previous work on IgG4-related interstitial nephritis within the 'Aims' section. However, the fact that this is previous work and not work from the current study needs to be made clear, with improved wording."

We have improved the wording in the introduction of the abstract, making it clear that we refer to work of others. 


\section{$\mathrm{OUH}$ \\ Odense \\ Universitetshospital}

6. marts 2010

Side $3 / 3$

Point 2: "In the 'Patients and Methods', it could be made slightly clearer at the bottom of page 4 if the seventh patient was described with a phrase such as 'In addition, a seventh patient was included, diagnosed with ....', or similar wording."

We have left the wording of the sentence of the bottom of page 4 unchanged, since we think it reads better then the proposal by referee two.

We hope that our changes meet your expectations.

Besides, I wish to state that

(a) the work is original;

(b) the work has not been, and will not be published, in whole, or in part, in any other journal;

(c) and all the authors have agreed to the contents of the manuscript in its submitted form.

Kind regards, sincerely yours, Sönke Detlefsen 